\title{
Efeito de Diferentes Fontes de Gordura na Dieta de Vacas Jersey sobre o Consumo, a Produção e a Composição do Leite ${ }^{1}$
}

\author{
Luciana Marta D’Almeida Duarte ${ }^{2}$, Waldyr Stumpf Júnior ${ }^{3}$, Vívian Fischer ${ }^{4}$, Luciane Elisete Salla ${ }^{2}$
}

RESUMO - Com o objetivo de investigar o efeito de diferentes fontes de gordura na dieta de vacas Jersey sobre os consumos de matéria seca (CMS), fibra em detergente neutro (CFDN) e extrato etéreo (CEE), sobre a composição e a produção de leite (PL), foram utilizadas oito vacas Jersey, distribuídas em dois quadrados Latinos (4 x 4). Os tratamentos utilizados foram: C = concentrado sem gordura; $\mathrm{SB}=$ concentrado com sebo bovino; GP = concentrado com gordura protegida comercial (sais de cálcio + óleo de palma); e GS = concentrado com grão de soja. Não houve diferença para os CMS e CFDN. O CEE foi mais elevado nos tratamentos que incluíram gordura nas dietas. Os tratamentos GP e SB proporcionaram produção leiteira (PL) e produção leiteira corrigida a 4\% de gordura (PLCG4\%) semelhantes entre si (25,6 e 23,6 kg/vaca/dia) e GP foi superior aos tratamentos C e GS, que resultaram em PLCG4\% de 23,4 e 22,9 kg/vaca/dia, respectivamente. A eficiência da produção de leite (PLCG4\%:CMS) diferiu entre tratamentos. O tratamento GP apresentou a melhor eficiência de produção $(1,50)$, apesar de semelhante ao tratamento C $(1,38)$. Os teores de gordura $(\mathrm{G})$, proteína total $(\mathrm{P})$, caseína $(\mathrm{C})$, sólidos totais (ST), sólidos totais desengordurados (STD), densidade (D) e índice crioscópico (IC) não diferiram entre os tratamentos. Os resultados indicam a viabilidade do uso de gordura nas dietas para vacas leiteiras de alta produção, observando-se aumento na produção e melhoria da eficiência de produção, sem alterações no consumo de alimentos e na composição do leite produzido.

Palavras-chave: eficiência, gordura protegida, grão soja, sebo, vacas alta produção

\section{Effects of Different Dietary Fat Sources on Intake and Milk Yield and Composition of Jersey Cows}

\begin{abstract}
Eight high-yielding Jersey cows were randomly assigned to two $4 \mathrm{x} 4$ Latin squares to study the effects of different dietary fat sources on intakes of dry matter (DMI), neutral detergent fiber (NDFI), and ether extract (EEI) as well as on milk yield and composition. The following treatments were used: concentrate with no added fat (control = C); concentrate plus tallow $(\mathrm{T})$; concentrate plus commercial ruminally protected fat (calcium salts + palm oil; PF); and concentrate plus whole soybean (WS). Both DMI and NDFI did not differ significantly among treatments. However, EEI was higher for cows fed diets containing the added fat sources than for those fed the $\mathrm{C}$ diet. Both milk yield and milk yield corrected for $4 \%$ fat (FCM) were highest on PF, intermediate on T, and lowest on C and WS diets. Cows fed PF had greater feed efficiency expressed as FCM/ DMI (1.50), compared with those fed T or WS diets but it was similar to C (1.38). Contents of milk fat, crude protein, casein, total solids, solids-nonfat, density, and the cryoscopic index all were not affected by dietary treatments. It can be concluded that addition of fat sources to diets of lactating Jersey cows is recommended because improved milk yield and feed efficiency with no deleterious effects on DMI and milk composition.
\end{abstract}

Key Words: efficiency, fat by pass, high-yielding cows, soybean grain, tallow

\section{Introdução}

No início da lactação, as vacas leiteiras de alta produção não consomem alimento suficiente para atender suas exigências energéticas. A produção máxima de leite geralmente ocorre entre a quarta e a oitava semana pós-parto e o consumo máximo de alimentos, entre a décima e a décima quarta semana, o que causa um "balanço energético negativo". Dessa forma, as vacas de alta produção mobilizam tecidos corporais, particularmente os depósitos de gordura, resultando em perda de peso e de condição corporal (NRC, 1989; Gagliostro \& Chilliard, 1992).

Entre as estratégias para aumentar a densidade energética da dieta de vacas no início da lactação, tem-se estudado a suplementação com lipídeos (Palmquist \& Mattos, 1978). A utilização de fontes de gordura de origem vegetal, como óleos vegetais e sementes oleaginosas e de gordura animal, como sebo, é uma das alternativas empregadas para aumentar a densidade energética na dieta. Os tipos de lipídeos empregados nas dietas podem influenciar a

\footnotetext{
1 Trabalho financiado pela Embrapa Clima Temperado, PPGZ - UFPEL.

2 Mestre em Produção Animal, PPGZ - UFPEL (luduarte@alternet.com.br).

${ }^{3}$ D.S., Pesquisador da Embrapa Clima Temperado (stumpf@cpact.embrapa.br).

4 D.S., Professor Adjunto do Departamento de Zootecnia - UFRGS. Bolsista do CNPq (vfried@portoweb.com.br).
} 
fermentação e a digestibilidade ruminal da fibra, por meio da supressão das bactérias celulolíticas e metanogênicas. Os lipídeos saturados comportam-se de forma menos prejudicial à flora microbiana. A utilização de lipídeos insaturados interfere no metabolismo ruminal, mas, por outro lado, seu efeito hipocolesterolêmico o torna desejável na composição do leite para a saúde humana (Palmquist \& Jenkins, 1980; Chalupa et al., 1984; Van Soest, 1994).

A redução da digestibilidade é decorrente de um mecanismo físico de recobrimento da fibra com gordura, dificultando o ataque microbiano e provocando efeitos tóxicos diretamente sobre certos microrganismos, além de redução na disponibilidade de cátions por se combinarem com os ácidos graxos (Palmquist \& Jenkins, 1980; Grummer et al., 1990).

Entre as opções de alimentação com dietas ricas em lipídeos, o grão de soja destaca-se pela sua disponibilidade regional, pelo elevado teor de ácidos graxos insaturados e pela grande aceitação pelos animais (Palmquist \& Mattos, 1978; Palmquist 1991; Rabello et al., 1996). Segundo Coppock \& Wilks (1991), a digestibilidade dos lipídeos dos grãos que a de óleos adicionados à dieta, provavelmente em razão da lenta liberação dos lipídeos dos grãos, não superando, dessa forma, a capacidade de hidrogenação dos microrganismos ruminais.

Outro produto que pode ser utilizado para o mesmo fim é o sebo bovino que, em geral, apresenta-se como um alimento de preço acessível e de fácil manuseio, sem problemas de palatabilidade pelos animais e digestibilidade de sua fração lipídica. Estudando os efeitos da adição de sebo bovino à dieta, Malafaia et al. (1996) não encontraram diferenças nos consumos voluntários de MS, MO, PB, FDN, carboidratos totais e NDT, porém, foi observada redução da fração protéica (caseína) quando sebo bovino foi adicionado à dieta de vacas leiteiras (Dunkley et al., 1977; Coppock \& Wilks, 1991; Eastridge \& Firkins, 1991; Bertrand et al., 1993; Grummer \& Melissa, 1993). O uso de suplementos gordurosos tende a diminuir o consumo, reduzindo, portanto, a síntese de proteína microbiana no rúmen, com redução, também, na proteína do leite (caseína). Com a adição de lipídeos na dieta, pode haver redução na síntese de caseína do leite (Dunkley et al., 1977; Coppock \& Wilks, 1991; Van Soest, 1994).

Este trabalho foi conduzido para se avaliar o efeito de diferentes fontes alternativas de gordura, produzi- das regionalmente, sobre o consumo, a produção e eficiência de produção e a composição do leite de vacas Jersey, no terço inicial de lactação.

\section{Material e Métodos}

O trabalho foi conduzido no Sistema de Pecuária de Leite - SISPEL, localizado na Estação Experimental Terras Baixas da Embrapa Clima Temperado, situada no município de Capão do Leão - RS.

Foram utilizadas oito vacas Jersey puras com peso vivo (PV) de $389 \pm 27 \mathrm{~kg}$ e produção diária de leite de $21 \pm 3 \mathrm{~kg}$. As vacas eram todas de $2^{\mathrm{a}}$ e $3^{\mathrm{a}}$ ordem de lactação, com 3,5 a 5 anos de idade e apresentavam escore corporal em torno de 3,5, no início do trabalho. Foram utilizados quatro tratamentos: Controle (C) - concentrado sem a inclusão de gordura, SB - concentrado com a inclusão de sebo bovino, GP - concentrado com a inclusão de gordura protegida comercial (sais de cálcio e óleo de palma) e GS - concentrado com a inclusão de grão de soja integral triturada. As dietas foram formuladas para serem isoprotéicas e, nos tratamentos com a adição de fontes de gordura, para serem isoenergéticas. A composição bromatológica dos ingredientes utilizados na sua formulação encontram-se, respectivamente, nas Tabelas 1, 2 e 3.

Logo após o parto, as vacas permaneceram por 24 a 30 horas com os bezerros em um piquete, sendo, após, distribuídas aleatoriamente nos tratamentos, de acordo com dois quadrados latinos balanceados $4 \times 4$, e colocadas em baias individuais. Todas as vacas passaram por um período pré-experimental em torno de $51 \pm 4$ dias, para adaptação às instalações e à rotina experimental. Durante este período, todos os animais receberam uma dieta padrão semelhante à do tratamento sem a inclusão de gordura (C).

As coletas de amostras, tanto de leite quanto de alimentos e sobras, e as pesagens dos animais foram feitas no período de coleta de dados. As vacas foram pesadas no primeiro e último dia de cada período de coleta de dados. O horário utilizado para obtenção do peso dos animais foi após a ordenha da manhã, antes da alimentação dos animais.

Os animais foram alimentados com uma dieta à base de silagem de milho e feno de alfafa picado. A relação volumoso:concentrado foi fixada na proporção de 55:45, permitindo-se sobrar o equivalente a $10 \%$ da mistura de volumosos. O concentrado foi fornecido três 
Tabela 1- Composição bromatológica dos ingredientes (valores expressos como porcentagem da matéria seca) Table 1 - Chemical composition of ingredients on \% of dry matter

\begin{tabular}{|c|c|c|c|c|c|c|c|}
\hline \multirow[t]{2}{*}{ Itens } & \multicolumn{7}{|c|}{$\begin{array}{l}\text { Ingrediente } \\
\text { Ingredient }\end{array}$} \\
\hline & $\begin{array}{l}\text { Silagem de milho } \\
\text { Corn silage }\end{array}$ & $\begin{array}{c}\text { Feno de alfafa } \\
\text { Alfafa hay }\end{array}$ & $\begin{array}{c}\text { Farelo de soja } \\
\text { Soybean meal }\end{array}$ & $\begin{array}{c}\text { Milho } \\
\text { Corn }\end{array}$ & $\begin{array}{l}\text { Grão de soja } \\
\text { Whole soybean }\end{array}$ & $\begin{array}{l}\text { Sebo } \\
\text { Tallow }\end{array}$ & $\begin{array}{l}\text { Gordura protegida } \\
\text { Protected fat }\end{array}$ \\
\hline $\operatorname{MS}(D M)$ & 29,22 & 87,40 & 85,82 & 88,00 & 86,62 & 99,00 & 96,00 \\
\hline $\mathrm{PB}(C P)$ & 7,52 & 22,20 & 49,15 & 8,50 & 37,63 & - & - \\
\hline $\mathrm{EE}(E E)$ & 4,69 & 1,61 & 1,56 & 4,30 & 18,00 & 99,50 & 84,00 \\
\hline $\mathrm{FDN}(N D F)$ & 61,78 & 47,70 & 18,62 & 9,00 & 27,76 & - & - \\
\hline $\mathrm{FDA}(A D F)$ & 33,72 & 27,95 & 11,90 & 3,00 & 19,38 & - & - \\
\hline $\mathrm{Ca}$ & 0,28 & 1,67 & 0,28 & 0,03 & 0,21 & - & 9,00 \\
\hline $\mathrm{P}$ & 0,53 & 0,35 & 0,56 & 0,29 & 0,55 & - & - \\
\hline
\end{tabular}

$\mathrm{MS}=$ matéria seca $(D M=$ dry matter $) ; \mathrm{PB}=$ proteína bruta $($ crude protein $) ; \mathrm{EE}=$ extrato etéreo $(E E=$ ether extract $) ; \mathrm{FDN}=$ fibra em detergente neutro (NDF = neutral detergent fiber); FDA = fibra em detergente ácido $(F D A=$ acid detergent fiber $) ; \mathrm{Ca}=$ cálcio $($ calcium $) ; \mathrm{P}=$ fósforo $(P=$ phosphorus $)$.

Tabela 2 - Proporção de ingredientes na dieta total (\% da matéria seca)

Table 2 - Ingredient composition of diet on \% of dry matter

\begin{tabular}{|c|c|c|c|c|}
\hline \multirow[t]{2}{*}{$\begin{array}{l}\text { Ingrediente } \\
\text { Ingredient }\end{array}$} & \multicolumn{4}{|c|}{$\begin{array}{c}\text { Tratamento** } \\
\text { Treatment } * *\end{array}$} \\
\hline & $\mathrm{C}$ & $\mathrm{SB}(T)$ & $\mathrm{GP}(P F)$ & $\mathrm{GS}(W S)$ \\
\hline Silagem de milho (Corn silage) & 26,13 & 27,02 & 27,26 & 26,54 \\
\hline Feno de alfafa (Alfafa hay) & 17,25 & 21,14 & 22,04 & 7,08 \\
\hline Milho grão (Corn grain) & 28,95 & 20,43 & 18,59 & 23,32 \\
\hline Sebo (Tallow) & - & 2,74 & - & - \\
\hline Grão de soja (Whole soybean) & - & - & - & 14,86 \\
\hline Gordura protegida (Protected fat) & - & - & 3,2 & - \\
\hline Fosfato bicálcico (Dicalcium phosphate) & 0,53 & 0,57 & 70,59 & 0,49 \\
\hline Calcário calcítico (Limestone) & 0,13 & 0,08 & - & 0,13 \\
\hline Mistura mineral* (Mineral mix) & 0,25 & 0,36 & 0,34 & 0,40 \\
\hline Bicarbonato de sódio (Sodium bicarbonate) & 0,63 & 0,64 & 0,65 & 0,64 \\
\hline
\end{tabular}

* Composição por quilograma de produto: Cálcio-230 g, Fósforo-90 g, Enxofre-15 g, Magnésio-20 g, Cobre-700 mg, Zinco-2700 mg Manganês-1250 mg, Cobalto-100 mg, lodo-80 mg, Selênio-20 mg, Ferro -2000 mg.

* Provided (per kg of DM): Calcium-230 g, Phosphorus- 90 g, Sulfur-15 g, Magnesium-20 g, Cupper- 700 mg, Zinc-2700 mg, Manganes 1250 mg, Cobalt $-100 \mathrm{mg}$, lodine $-80 \mathrm{mg}$. Selenium - $20 \mathrm{mg}$. Iron - $2000 \mathrm{mg}$

${ }^{* *} \mathrm{C}=$ controle; $\mathrm{SB}=$ sebo; $\mathrm{GP}=$ gordura protegida; $\mathrm{GS}$ = grão de soja

${ }^{*} C=$ control; $T=$ tallow; $P F=$ protected fat $W S=$ whole soybean .

vezes ao dia, após a ordenha da manhã, ao meio-dia, e após a ordenha da tarde, enquanto o volumoso foi fornecido duas vezes ao dia, após as ordenhas.

No tratamento em que se utilizou como fonte de gordura o sebo bovino, este foi aquecido até tornar-se líquido e foi aspergido sobre a mistura dos ingredientes que faziam parte do tratamento. Os concentrados dos demais tratamentos foram misturados de acordo com a sua composição. O alimento concentrado foi fornecido separadamente do volumoso, a fim de que os animais consumissem a quantidade desejada e fosse possível quantificar o consumo de volumoso e de concentrado, por meio das sobras diárias dos alimentos fornecidos e das sobras para cada vaca, em cada período experimental. As amostras de alimentos fornecidos e sobras foram pesadas e, imediatamente, acondicionadas e guardadas, para análises futuras. O consumo de matéria seca de cada tratamento foi obtido pela diferença entre a oferta e o remanescente da matéria seca da dieta oferecida para cada animal, após 24 horas de consumo.

Posteriormente, as amostras dos alimentos fornecidos e das sobras foram descongeladas, pré-secas em estufa de circulação forçada à $55^{\circ} \mathrm{C}$, por 72 horas, e trituradas em moinho tipo Willey com peneira de 30 mesh. As determinações bromatológicas foram efetuadas e determinaram-se as porcentagens de matéria seca (MS), proteína bruta $(\mathrm{PB})$ e de extrato etéreo (EE), segundo os métodos descritos pela AOAC (1990). Os teores de fibra em detergente neutro (FDN) e fibra em detergente ácido (FDA) foram determinadas pelo método proposto por Goering \& Van Soest (1991) e os de 
Tabela 3 - Composição bromatológica das dietas experimentais, em porcentagem de matéria seca, proteína bruta (PB), fibra em detergente neutro (FDN), fibra em detergente ácido (FDA), extrato etéreo (EE), cálcio $(\mathrm{Ca})$, fósforo $(\mathrm{P})$ e nutrientes digestíveis totais (NDT)

Table 3 - Chemical composition of diets expressed as percent of dry matter, crude protein (CP), neutral detergent fiber (NDF), acid detergent fiber ( $A D F)$, ether extract $(E E)$, calcium $(\mathrm{Ca})$, phosphorus $(P)$ and total digestive nutrient (TDN)

\begin{tabular}{|c|c|c|c|c|}
\hline \multirow[t]{2}{*}{$\begin{array}{l}\text { Fração nutritiva } \\
\text { Item }\end{array}$} & \multicolumn{4}{|c|}{$\begin{array}{l}\text { Tratamento** } \\
\text { Treatment } * *\end{array}$} \\
\hline & $\mathrm{C}$ & $\mathrm{SB}(T)$ & $\mathrm{GP}(P F)$ & $\mathrm{GS}(W S)$ \\
\hline $\mathrm{PB}(C P)$ & 17,72 & 18,97 & 17,94 & 17,82 \\
\hline $\mathrm{FDN}(N D F)$ & 32,98 & 33,68 & 33,88 & 33,58 \\
\hline $\mathrm{FDA}(A D F)$ & 18,86 & 19,52 & 19,69 & 19,59 \\
\hline $\mathrm{EE}$ & 3,63 & 6,28 & 6,29 & 6,28 \\
\hline $\mathrm{Ca}$ & 0,65 & 0,67 & 0,94 & 0,66 \\
\hline $\mathrm{P}$ & 0,41 & 0,42 & 0,43 & 0,41 \\
\hline $\mathrm{NDT}^{*}(T D N)$ & 69,79 & 72,23 & 72,86 & 71,00 \\
\hline
\end{tabular}

cálcio e fósforo, pelo método preconizado por Tedesco et al. (1985).

A ordenha foi efetuada duas vezes ao dia, às $7 \mathrm{e}$ $17 \mathrm{~h}$, em uma sala tipo espinha de peixe com capacidade para oito vacas. As amostras de leite foram coletadas individualmente, em quatro dias intercalados, dentro da semana de coleta (dias 1, 3, 5 e 7), nas ordenhas da manhã e da tarde e foram rapidamente resfriadas. As amostras individuais das ordenhas da manhã e da tarde foram misturadas e levadas para análise da composição físico-química. O teor de gordura do leite foi obtido pelo método de Gerber (Coelho \& Rocha, 1977), o teor de PB do leite, pelo método de Kjeldahl, utilizando-se o fator 6,38 multiplicado pelo teor de nitrogênio total (AOAC, 1990), e, para a densidade (D), foi utilizado o termolactodensímetro de Quebec, aferido a $15^{\circ} \mathrm{C}$. Os outros componentes, como extrato seco total (EST) e extrato seco desengordurado (ESD), foram determinados pelo disco de "Ackermann".

O delineamento experimental adotado foi o quadrado latino rotativo $(4 \times 4)$ duplo, com uma semana de intervalo entre eles, quatro tratamentos, oito vacas e quatro períodos experimentais. As variáveis relacionadas à produção e composição do leite, ao peso vivo, ao consumo de MS, FDN e EE foram submetidas à análise de variância, segundo o seguinte modelo estatístico:

$$
\mathrm{Y}_{\mathrm{ijklm}}=\mathrm{U}+\underset{\mathrm{E}_{\mathrm{ijklm}}}{\mathrm{Q}_{\mathrm{i}}}+\underset{\mathrm{j}}{\left.\mathrm{P}_{\mathrm{j}}\left(\mathrm{Q}_{\mathrm{i}}\right)+\mathrm{Q}_{\mathrm{i}}\right)+\mathrm{T}_{1}+\mathrm{Q}_{\mathrm{i}} \mathrm{T}_{1}+}
$$

em que $\mathrm{U}=$ média geral do experimento; $\mathrm{Q}_{\mathrm{i}}=$ efeito de quadrado latino $(\mathrm{n}=2) ; \mathrm{P}_{\mathrm{j}}\left(\mathrm{Q}_{\mathrm{i}}\right)=$ efeito de período hierarquizado dentro de quadrado latino $(n=4)$; $\mathrm{V}_{\mathrm{k}}\left(\mathrm{Q}_{\mathrm{i}}\right)=$ efeito de animal hierarquizado dentro de quadrado latino $(\mathrm{n}=8) ; \mathrm{T}_{1}=$ efeito de tratamento, ou seja, das dietas $(\mathrm{n}=4) ; \mathrm{Q}_{\mathrm{i}} \mathrm{T}_{1}=$ efeito da interação entre tratamento e quadrado latino $(\mathrm{n}=8) ; \mathrm{E}_{\mathrm{ijk} \mathrm{lm}}=$ resíduo.

Para comparação de médias, foi utilizado o teste Tukey a 5\% de significância e o programa estatístico SAS versão 6.12 (UFV, 1989).

\section{Resultados e Discussão}

Os resultados referentes ao consumo médio de MS, FDN e EE, para as dietas contendo diferentes fontes de gordura, podem ser observados na Tabela 4 . Não foi observado efeito das dietas $(\mathrm{P}>0,05)$ sobre o consumo médio de MS e FDN. Mesmo havendo aumento da densidade energética em função da adição de gordura nos tratamentos SB, GP e GS, o que elevou $(\mathrm{P}<0,05)$ o consumo de gordura dessas dietas em relação ao tratamento $\mathrm{C}$, o consumo de $\mathrm{MS}$ não foi reduzido. Esta situação provavelmente tenha decorrido das características próprias dos alimentos, relativamente inertes no ambiente ruminal (gordura saturada - sebo bovino), potencialmente reativos, mas na forma esterificada (gordura insaturada na forma protegida óleo de palma esterificado), ou potencialmente reativo, mas com lenta liberação (gordura insaturada - grãos de soja triturados).

Uma importante consideração para se obter resultados satisfatórios com a utilização de gordura na dieta de vacas leiteiras é maximizar o consumo de forragem. Os valores obtidos neste trabalho, para os consumos de MS, estão acima daqueles observados por Palmquist \& Conrad (1978), que encontraram consumos variando de 2,97 a 3,40 kg de MS/100 kg PV e de 2,90 a 3,19 kg/100 kg de PV, respectivamente, para vacas Jersey e Holandês.

Wu et al. (1993), utilizando dietas à base de gordura protegida (sais de $\mathrm{Ca}+$ óleo de palma), sebo bovino e ácidos graxos protegidos por cristalização a frio, com vacas da raça Holandês, não encontraram diferenças nos consumos de MS na dieta, que variaram de 3,71 a 4,45 kg de MS/100 kg PV. 
O consumo de fibra em detergente neutro (CFDN) não diferiu entre os tratamentos $(\mathrm{P}>0,05)$, mas esses valores estão acima daqueles sugeridos pelo NRC (1989), de 1,2 $\pm 0,1 \mathrm{~kg} / 100 \mathrm{~kg}$ PV, para maximizar o consumo de MS e a produção de leite. A quantidade de MS consumida pela vaca leiteira depende de vários fatores, incluindo-se o nível de produção de leite, o estádio da lactação, as condições ambientais, o peso vivo, o manejo, o tipo e a qualidade dos alimentos, especialmente volumosos (NRC, 1989). Possivelmente, o elevado consumo foi resultado do alto potencial produtivo dos animais, associado ao estádio de lactação em que se encontravam (no pico de consumo) e à dieta com elevada qualidade de volumoso.

Os resultados obtidos estão de acordo com os relatados por Schingoethe \& Casper (1991), Holter et al. (1992) e Grummer \& Melissa (1993), mas divergem dos dados descritos por Canale et al. (1990), que, trabalhando com gordura protegida e diferentes níveis de FDN, encontraram aumento do consumo de MS e FDN, tanto em kg/dia quanto em kg/100 kg PV.

Houve diferença $(\mathrm{P}<0,05)$ para a ingestão total de extrato etéreo. Os tratamentos com adição de gordura, SB, GP e GS foram semelhantes entre si, mas superiores ao consumo de $\mathrm{EE}$ do $\mathrm{C}$, em razão da adição de gordura (Tabela 4 ).

Os valores encontrados para o peso vivo médio (PV) dos animais, as produções diária de leite (PL) e de leite corrigida para 4\% de gordura (PLCG4\%), a composição química e as características físicas do leite podem ser observados na Tabela 5 .
Os pesos vivos médios dos animais não diferiram entre os tratamentos $(\mathrm{P}>0,05)$, o que, possivelmente, seja explicado pelo fato de o consumo de MS não ter diferido entre os tratamentos. Esses resultados estão de acordo com os encontrados por Eastridge \& Firkins (1991) e Grant \& Weidner (1992).

Os tratamentos GP e SB apresentaram PLCG 4\% semelhantes entre si, porém, GP proporcionou aumento médio de 2,0 kg de leite por vaca e por dia na produção. O tratametno GP apresentou aumento de 9,4 e 11,8\% na produção de leite corrigido a $4 \%$ de gordura, em relação aos tratamentos C e GS (Tabela 5).

Gagliostro \& Chilliard (1992) encontraram efeito positivo sobre a produção de leite de $1,0 \mathrm{~kg} / \mathrm{vaca} / \mathrm{dia}$, para o consumo médio de 0,59 e $0,94 \mathrm{~kg} / \mathrm{vaca} /$ dia de EE adicionado na MS, na utilização de gordura saturada vs gordura protegida, respectivamente.

O consumo médio de EE para as dietas SB, GP e GS correspondeu à adição de $0,378 \mathrm{~kg} /$ dia, proveniente de cada fonte de gordura estudada sobre a dieta. $\mathrm{O}$ aumento da produção de leite (PLCG 4\%) nos tratamentos com a utilização de gordura protegida (GP) e sebo bovino (SB), como fonte de gordura saturada, deve-se, provavelmente, ao melhor aproveitamento dos ácidos graxos de cadeia longa da gordura protegida para a síntese do leite na glândula mamária; ou ao fato de o sebo bovino apresentar em sua composição elevada proporção de ácidos graxos de cadeia longa e comportar-se como uma fonte de gordura praticamente inerte no rúmen. Desta forma, as dietas dos tratamentos GP e SB possivelmente não interferiram na fermentação ruminal.

Tabela 4 - Consumo médio diário de matéria seca (CMS), fibra em detergente neutro (CFDN) e extrato etéreo (CEE) por tratamento

Table 4 - Average intakes of dry matter (DMI), neutral detergent fiber (NDFI), and ether extract (EEI) for each treatment

\begin{tabular}{|c|c|c|c|c|c|}
\hline \multirow[t]{2}{*}{ Item } & \multicolumn{4}{|c|}{$\begin{array}{c}\text { Tratamento* } \\
\text { Treatment* }\end{array}$} & \multirow[b]{2}{*}{$\mathrm{CV}(\%)$} \\
\hline & $\mathrm{C}$ & $\mathrm{SB}(T)$ & $\mathrm{GP}(P F)$ & GS $(W S)$ & \\
\hline CMS (kg/dia) & $17,07 \mathrm{a}$ & $17,32 \mathrm{a}$ & $16,99 a$ & $17,01 \mathrm{a}$ & 5,01 \\
\hline \multicolumn{6}{|l|}{ DMI (kg/day) } \\
\hline $\mathrm{kg} / 100 \mathrm{~kg}$ de $\mathrm{PV}(B W)$ & $4,51 \mathrm{a}$ & $4,57 \mathrm{a}$ & $4,48 \mathrm{a}$ & $4,52 \mathrm{a}$ & 5,66 \\
\hline $\mathrm{g} / \mathrm{kg} 0,75$ & $199 a$ & $201 \mathrm{a}$ & $197 \mathrm{a}$ & $199 a$ & 5,47 \\
\hline CFDN (kg/dia) & $5,62 \mathrm{a}$ & $5,74 \mathrm{a}$ & $5,54 \mathrm{a}$ & $5,63 \mathrm{a}$ & 8,58 \\
\hline \multicolumn{6}{|l|}{ NDFI (kg/day) } \\
\hline kg/100kg PV $(B W)$ & $1,48 \mathrm{a}$ & $1,51 \mathrm{a}$ & $1,46 \mathrm{a}$ & $1,49 \mathrm{a}$ & 9,18 \\
\hline $\mathrm{CEE}(\mathrm{kg} / \mathrm{dia})$ & $0,627 \mathrm{~b}$ & $1,026 \mathrm{a}$ & $1,139 a$ & $1,070 \mathrm{a}$ & 15,95 \\
\hline \multicolumn{6}{|l|}{$E E I(\mathrm{~kg} /$ day $)$} \\
\hline $\mathrm{kg} / 100 \mathrm{~kg}$ de $\mathrm{PV}(B W)$ & $0,166 \mathrm{~b}$ & $0,274 \mathrm{a}$ & $0,301 \mathrm{a}$ & $0,284 a$ & 14,91 \\
\hline
\end{tabular}

Médias na mesma linha seguidas de letras distintas diferem $(P<0,05)$ entre si pelo teste Tukey.

Means in the same row with different superscripts differ $(P<0.05)$ according to Tukey test.

${ }^{* *} \mathrm{C}=$ controle; $\mathrm{SB}=$ sebo; $\mathrm{GP}=$ gordura protegida; $\mathrm{GS}=$ grão de soja.

${ }^{* *} C=$ control; $T=$ tallow; $P F=$ protected fat; $W S=$ whole soybean. 
Segundo Kronfeld (1982), a quantidade de glicose na glândula mamária é o principal fator determinante do volume de leite. O aumento da extração de ácidos graxos de cadeia longa do sangue pela glândula mamária, em decorrência de seu fornecimento na gordura da dieta, decresce a síntese de ácidos graxos de cadeias curtas e médias. Essa síntese requer a utilização de glicose como fornecedora de agentes redutores NADPH, via ciclo das pentoses. Desta forma, pode haver maior disponibilidade de glicose, que pode ser dirigida para outros processos de produção de leite (Palmquist \& Jenkins, 1980). A utilização de gordura pode ter propiciado uma queda na utilização da glicose (Kronfeld et al., 1980).

A utilização de gorduras protegida e saturada nos tratamentos GP e SB pode, também, ter influenciado favoravelmente a digestibilidade da fibra em relação ao tratamento com a inclusão de grão de soja, que, por apresentar maior proporção de ácidos graxos insaturados, pode ter provocado interferência no ambiente ruminal. Jenkins \& Palmquist (1984) salientaram o efeito dos ácidos graxos sobre a fibra quando gorduras não-protegidas são fornecidas na dieta.

A eficiência de utilização de alimentos medida neste trabalho, por meio da relação entre a PLCG 4\% e o consumo total de matéria seca (CMS), apresentou diferença $(\mathrm{P}<0,05)$ entre tratamentos (Tabela 5). $\mathrm{O}$ tratamento com a inclusão de gordura protegida foi semelhante ao C. A eficiência alimentar do GP foi superior $(\mathrm{P}<0,05)$ à dos tratamentos $\mathrm{SB}$ e GS, que, no entanto, não diferiram de $\mathrm{C}$. A maior eficiência alimentar deve-se, possivelmente, à alta concentração de energia digestível e à maior eficiência de utilização da energia da gordura, especialmente da gordura protegida. O tratamento com gordura protegida apresentou eficiência equivalente a $1,50 \mathrm{~kg}$ de leite corrigido com $4 \%$ de gordura por $\mathrm{kg}$ de MS consumida na dieta. É interessante observar que as dietas dos tratamentos apresentaram teor de FDN em torno de 33\%.

Wu et al. (1993), em estudo com vacas da raça Holandês, alimentadas com uma dieta controle com $3,7 \%$ de ácidos graxos e três dietas suplementadas com sebo bovino $(6,2 \% \mathrm{EE})$, gordura protegida (sais de cálcio + óleo de palma) $(6,1 \% \mathrm{EE})$ e gordura protegida por cristalização à frio $(6,2 \% \mathrm{EE})$, encontraram eficiência alimentar, com leite corrigido para $3,5 \%$ de gordura (PLCG 3,5\%/CMS), variando de 1,25 a 1,36 . As dietas apresentavam concentração média de de $31 \%$ de FDN e os resultados de eficiência não foram significativos.

Grant \& Weidner (1992), trabalhando com oito vacas primíparas da raça Holandês, alimentadas com dietas suplementadas com grão de soja, apresentando teores de EE de 3,8 e $6,0 \%$ e de FDN médios de $29,5 \%$, encontraram eficiência de produção, com leite corrigido para $4 \%$ de gordura (PLCG $4 \% / \mathrm{CMS}$ ) va-

Tabela 5 - Efeitos de diferentes fontes de gordura na dieta sobre o rendimento e a composição do leite de vacas leiteiras lactantes

Table 5 - Effects of different dietary fat sources on milk yield and composition of lactating dairy cows

\begin{tabular}{|c|c|c|c|c|c|}
\hline \multirow[t]{2}{*}{ Item } & \multicolumn{4}{|c|}{$\begin{array}{c}\text { Tratamento* } \\
\text { Treatment } *\end{array}$} & \multirow[b]{2}{*}{$\mathrm{CV}(\%)$} \\
\hline & $\mathrm{C}$ & $\mathrm{SB}(T)$ & $\mathrm{GP}(P F)$ & $\mathrm{GS}(W S)$ & \\
\hline $\mathrm{PL}(M P)$ & $21,4 b$ & $21,9 \mathrm{ab}$ & $22,7 \mathrm{a}$ & $21,2 b$ & 2,90 \\
\hline PLCG $4 \%(4 \% F C M)$ & $23,4 b$ & $23,6 a b$ & $25,6 \mathrm{a}$ & $22,9 b$ & 6,30 \\
\hline PLCG4\%/CMS (4\% FCM/DMI) & $1,38 \mathrm{ab}$ & $1,36 b$ & $1,50 \mathrm{a}$ & $1,35 b$ & 7,17 \\
\hline Proteína total (Crude protein yield) & $0,61 \mathrm{a}$ & $0,72 \mathrm{a}$ & $0,73 \mathrm{a}$ & $0,71 \mathrm{a}$ & 8,06 \\
\hline Proteína (Protein content) & $3,36 \mathrm{a}$ & $3,35 \mathrm{a}$ & $3,22 \mathrm{a}$ & $3,36 \mathrm{a}$ & 4,26 \\
\hline Caseína (Casein content) & $2,45 \mathrm{a}$ & $2,71 \mathrm{a}$ & $2,48 \mathrm{a}$ & $2,49 a$ & 3,01 \\
\hline Sólidos totais (Total solids) & $13,85 \mathrm{a}$ & $13,59 a$ & $13,83 \mathrm{a}$ & $13,70 \mathrm{a}$ & 1,90 \\
\hline Sólidos totais desengordurados (Solids-nonfat) & $9,27 \mathrm{a}$ & $9,05 \mathrm{a}$ & $8,98 \mathrm{a}$ & $9,07 \mathrm{a}$ & 1,63 \\
\hline
\end{tabular}

Médias na mesma linha seguidas de letras distintas diferem $(P<0,05)$ entre si pelo teste Tukey.

Means in the same row with different superscripts differ $(P<0.05)$ according to Tukey test.

${ }^{*} \mathrm{C}=$ controle; $\mathrm{SB}=$ sebo; $\mathrm{GP}=$ gordura protegida; $\mathrm{GS}=$ grão de soja.

${ }^{*} C=$ control; $S B=$ tallow; $G P=$ protected fat $; G S=$ whole soybean. 
riando de 1,25 a 1,56. Jenkins \& Jenny (1992) encontraram, para a eficiência de produção de leite (PLCG 4\%/CMS), utilizando dez vacas da raça Holandês alimentadas com dietas contendo óleo de canola e gordura protegida, valores entre 1,27 e 1,50. Canale et al. (1990) estudaram os efeitos de dietas com gordura protegida (sais de cálcio + ácidos graxos) e diferentes níveis de FDN. Os autores observaram eficiência de utilização da matéria seca (PLCG \%/CMS) decrescente, variando de 1,53 a 1,32 , à medida que a concentração de FDN diminuiu de 31 para 25\% na MS da dieta. Essa situação deveuse, provavelmente, à redução no $\mathrm{pH}$ ruminal, como conseqüência da queda do teor de FDN da dieta, o que pode ter ocasionado aumento na taxa de passagem e redução da digestibilidade dos componentes da dieta.

Palmquist \& Conrad (1978) observaram que a produção de leite tendeu a aumentar com dietas contendo alto teor de gordura. Entretanto, ao trabalharem com vacas das raças Holandês e Jersey, esses autores observaram interação significativa entre dieta e raça para eficiência da produção leiteira. A produção das vacas Jersey continuou aumentando, como resposta aos níveis mais elevados de gordura na dieta, como ocorreu com vacas Holandesas. Fatores genéticos ligados ao melhor aproveitamento da gordura da dieta, nas raças de pequeno porte, para produção de leite, podem ser um diferencial em relação às raças de grande porte, como a Holandês.

A suplementação de dietas, utilizando-se lipídeos como fonte de energia, pode ter efeitos marcantes na produção e composição do leite, assim como nos teores de proteína (De Peters \& Cant, 1992), gordura, sólidos totais e outros componentes do leite (Palmquist \& Jenkins, 1980).

Os resultados referentes à produção de gordura no leite, tanto em $\mathrm{kg} / \mathrm{vaca} / \mathrm{dia}$, quanto em porcentagem, não diferiram entre os tratamentos $(\mathrm{P}>0,05)$ (Tabela 5). Têm-se observado diferentes resultados em relação à gordura no leite, em função de variações nas dietas dos animais, principalmente em trabalhos que utilizam diferentes fontes de gordura (saturada vs insaturada), carboidratos solúveis e diferentes níveis de fibra. O teor de gordura do leite, neste experimento, não apresentou variações significativas, corroborando os dados relatados por Pantoja et al. (1994) e divergindo dos de Banks et al. (1984) e Eastridge \& Firkins (1991). A semelhança em relação aos percentuais e à produção total de gordura do leite pode ser decorrente da não-diferença no consumo dos animais, tanto em relação à $\mathrm{MS}$ como à $\mathrm{FDN}$, não havendo, também, efeito negativo da ingestão de gordura sobre o ambiente ruminal.

Os teores de proteína não foram alterados pelos tratamentos $(\mathrm{P}>0,05)$ (Tabela 5). Efeito negativo sobre o teor protéico seria menos acentuado no terço inicial da lactação (Gagliostro \& Chilliard, 1992). Outros autores sustentam o contrário; que a probabilidade de afetar negativamente o teor protéico do leite, por meio da suplementação lipídica, seria maior no início da lactação, em razão do balanço protéico negativo associado a este estado fisiológico, ou seja, há uma deficiência de aminoácidos para abastecer a alta síntese de proteína na glândula mamária (Wu \& Huber, 1994).

Casper \& Schingoethe (1989) e Coppocck \& Wilks (1991) atribuíram a redução no teor de proteína no leite, quando utilizaram gorduras nas dietas, ao efeito do menor consumo de alimento e à redução na síntese protéica microbiana. Todavia, neste trabalho, não se constataram diferenças de consumo entre as dietas (Tabela 4).

Palmquist (1991) utilizou diferentes fontes e níveis de gordura para vacas leiteiras e não encontrou alterações nos percentuais de gordura e proteína no leite. Os dados resultantes do teor protéico do leite, neste experimento, estão de acordo com os encontrados por Stern et al. (1985), Holter et al. (1992), Deresz et al. (1996). Astrup et al. (1974), por sua vez, trabalhando com óleos de coco e de soja protegidos, para vacas leiteiras, obtiveram aumento significativo no teor de proteína do leite.

Os percentuais de ST e STD não diferiram entre os tratamentos $(\mathrm{P}>0,05)$ (Tabela 5). Os resultados encontrados para os percentuais de sólidos totais e sólidos totais desengordurados, em experimentos que empregam dietas lipídicas, geralmente acompanham os resultados do teor protéico do leite, ou seja, há um reflexo de um sobre o outro e, portanto, as causas que levam à queda nos teores de proteína geralmente são as mesmas para os teores de sólidos totais e sólidos totais desengordurados (Umphrey et al.,1989; Holter et al., 1992), observando-se diminuição nos teores de sólidos em função da redução no consumo de alimentos e, conseqüentemente, na atividade ruminal e na produção de proteína microbiana. Em trabalhos discutidos anteriormente, foram encontrados, também, valores reduzidos para os sólidos totais do leite (Smith et al., 
1978, 1981; Casper \& Schingoethe, 1989). Shauffet al. (1992) e Deresz (1996) verificaram que os teores de proteína e sólidos do leite não foram alterados em dietas com adição de gordura, o que está de acordo com os resultados obtidos no presente trabalho.

A proteína total do leite é composta por três frações: proteínas do soro (17,2\%), nitrogênio nãoprotéico (NNP) (4,9\%) e caseína (77,9\%), a qual, juntamente com a proteína do soro, é considerada como proteína verdadeira (De Peters \& Cant, 1992). Não foi verificada diferença $(\mathrm{P}>0,05)$ nos teores de caseína entre os tratamentos (Tabela 5). Segundo De Peters \& Cant (1992), a suplementação de gordura pode reduzir o percentual de caseína, que possui importância para a indústria de laticínios, principalmente de queijo. No entanto, outros autores, ao trabalharem com gordura na dieta, não encontraram alterações para os valores de caseína (Coppock \& Wilks, 1991; Schauff et al., 1992; Jenkins \& Jenny, 1992). A redução na caseína pode ocorrer em função da diminuição da atividade ruminal causada pela redução de consumo dos animais, com reflexos sobre a produção de proteína microbiana e o aporte de aminoácidos à glândula mamária. Mohamed et al. (1988) observaram variação de de 78,6 a 80,0 no percentual de caseína em relação à proteína total do leite. Neste trabalho, a variação no percentual de caseína em relação ao de proteína foi de 72,9 a $80,9 \%$. Maior variação nos teores de caseína tem reflexos diretos sobre a produção de derivados do leite, principalmente sobre a produção de queijos.

Observa-se que os dados de densidade e crioscopia foram semelhantes, não havendo diferença $(\mathrm{P}>0,05)$ entre os tratamentos (Tabela 5). Embora não tenham tido influência dos tratamentos, estes dados permaneceram dentro dos limites recomendados e referenciados pelo RISPOA (BRASIL, 1980) e, de alguma forma, servirão como dados comparativos para futuros experimentos com a suplementação de lipídeos na dieta de vacas leiteiras.

\section{Conclusões}

A inclusão de gordura protegida na dieta de vacas leiteiras da raça Jersey, no período inicial da lactação, aumenta a produção de leite e a eficiência de produção, sem influenciar sua composição e a ingestão de alimentos.

A utilização de sebo bovino poderá ser recomendada na dieta de vacas leiteiras, caso não haja impedimento de comercialização e utilização para a alimentação animal.

\section{Literatura Citada}

ASSOCIATION OF OFFICIAL ANALYTICAL CHEMISTS AOAC. Official methods of analysis. 12.ed. Washington, 1990. 1094p.

ASTRUP, H.N.; VIK-MO, L.; EKERN, A. et al. Feeding protected and oils to dairy cows. Journal of Dairy Science, v.59, n.3, p.426-430, 1974.

BANKS, W.; CLAPPERTON, J. L.; GIRDLER, A. K. et al. Effect of inclusion of different forms of dietary fatty acid on the yield and composition of cows milk. Journal of Dairy Research, v.51, p.387, 1984.

BERTRAND, J.A.; JENQUINS, T.C.; PARDUE, F.E. Interaction of acid detergent fiber and tallow in lacting dairy cattle diets. Journal of Dairy Science, v.76, n.12, p.181 (Supplement 1), 1993.

BRASIL - Ministério da Agricultura. R.I.I.S.P.O.A. Regulamento da Inspeção Industrial e Sanitária de Produtos de Origem Animal (Aprovado pelo decreto no 30691 , de 20/03/ 1952, alterado pelo decreto no 1255 , de 25/06/1952) Brasília, 1980. 66p.

CANALE, C.J.; BURGESS, P.L.; MULLER, L.D. et al. Calcium salts of fatty acids in diets that differ in neutral detergent fiber: Effect on lactation performance and nutrient digestibility. Journal of Dairy Science, v.73, n.4, p.1031-1038, 1990.

CASPER, D.P.; SCHINGOETHE, D.J. Model to describe and alleviate milk protein depression in early lactation dairy cows fed a high fat diet. Journal of Dairy Science, v.72, n.12, p. 3327-3335, 1989.

CHALUPA, W.; RICKABAUGH, B.; KRONFELD, D.S. et al. Rumen fermentation in vitro as influenced by long chain fatty acids. Journal of Dairy Science, v.67, n.7, p.1439-1444, 1984.

COELHO, D.T.; ROCHA, J.A.A. Práticas de processamento de produtos animais. Viçosa, MG: Universidade Federal de Viçosa, 1977. 79p.

COPPOCK, C.E.; WILKS, D.L. Supplemental fat in high-energy rations for lactating cows: effects on intake, digestion, milk yield, and composition. Journal of Animal Science, v.69, p.3826-3837, 1991.

DePETERS, E.J.; CANT, J.P. Nutritional factors influencing the nitrogen composition of bovine milk: a review. Journal of Dairy Science, v.75, n.8, p.2043-2070, 1992

DERESZ, F.; FERNANDES, A.M.; MATOS, L.L. et al. Utilização da soja-grão crua na alimentação de vacas leiteiras de alta produção. Revista da Sociedade Brasileira de Zootecnia, v.25, n.1, p.113-124, 1996.

DUNKLEY, W.L.; SMITH, N.E.; FRANKE, A.A. Effects of feeding protected tallow on composition of milk and milk fat. Journal of Dairy Science, v.60, n.12, p. 1863 1869, 1977.

EASTRIDGE, M.L.; FIRKINS, J.L. Feeding hydrogenated fatty acids and triglycerides to lactating dairy cows. Journal of Dairy Science, v.74, n.8, p.2610-2616, 1991.

GAGLIOSTRO, G.A.; CHILLIARD, Y. Revisión bibliográfica. Utilización de lípidos protegidos en nutrición de vacas lecheras. I. Efecto sobre la producción y la composición de la leche y sobre la ingestión de materia seca y energía. Revista Argentina de Produción Animal, v.12, n.1, p.1-15, 1992.

GOERING, H.K.; Van SOEST, P.J. Forage fiber analysis apparatus, reagents, procedures and some applications. Washington: U.S.D.A., 1991. 79p. 
GRANT, R.J.; WEIDNER, S.J. Effect of fat from whole soybeans on performance of dairy cows fed rations differing in fiber level and particle size. Journal of Dairy Science, v.75, n.10, p.2742-2751, 1992.

GRUMMER, R.R.; MELISSA, L.L. Rumen fermentation and lactation performance of cows fed roasted soybeans and tallow. Journal of Dairy Science, v.76, n.9, p.2674-2681, 1993.

GRUMMER, R.R.; HATFIELD, M.L.; DENTINE, M.R. Acceptability of fat supplements in four dairy herds. Journal of Dairy Science, v.73, n.3, p.852-857, 1990.

HOLTER, J.B.; HAYES, H.H.; URBAN JR., W.E. Energy balance and lactation response in Holstein cows supplemented with cottonseed with or without calcium soap. Journal of Dairy Science, v.75, n.6, p.1480-1494, 1992.

JENKINS, T.C.; JENNY, B.F. Nutrient digestion and lactation performance of dairy cows fed combinations of prilled fat and canola oil. Journal of Dairy Science, v.75, n.3, p.796-803, 1992.

JENKINS, T.C.; PALMQUIST, D.L. Effect of fatty acids or calcium soaps on rumen and total nutrient digestibility of dairy rations. Journal of Dairy Science, v.67, n.5, p.978-986, 1984.

KRONFELD, D.S.; DONOGHUE, S.; NAYLOR, J.M. et al. Metabolic effects of feeding protected tallow to dairy cows. Journal of Dairy Science, v.63, n.4, p.545-552, 1980.

KRONFELD, D.S. Major metabolic determinants of volume, mammary efficiency and spontaneous Ketosis in dairy cows. Journal of Dairy Science, v.65, n.11, p.2204, 1982.

MALAFAIA, P.A.M.; FILHO, S.C.V.; SILVA, J.F.C. et al. Sebo bovino em rações para vacas em lactação. 1. consumo dos nutrientes, produção e composição do leite. Revista da Sociedade Brasileira de Zootecnia, v.25, n.1, p.153163,1996

MOHAMED, O.E.; SATTER, L.D.; GRUMMER, R.R. et al. Influence of dietary cottonseed and soybean on milk production and composition. Journal of Dairy Science, v.71, n.10, p.2677-2688, 1988 .

NATIONAL RESEARCH COUNCIL - NRC. Nutrient requirements of dairy cattle. 6.ed. Washington, D.C.: National Academy Press, 1989. 157p.

PALMQUIST, D.L. Influence of source and amount of dietary fat on digestibility in lacting cows. Journal of Dairy Science, v.74, n.4, p.1351-1360, 1991.

PALMQUIST, D.L.; CONRAD, H.R. High fat rations for dairy cows. Effects on feed intake, milk and fat production, and plasma metabolites. Journal of Dairy Science, v.61, n.7, p.890-901, 1978.

PALMQUIST, D.L.; JENKINS, T.C. Fat in lactation rations: Review. Journal of Dairy Science, v.63, n.1, p.1-14, 1980.

PALMQUIST, D.L.; MATTOS, W. Turnover of lipoproteins and transfer to milk fat dietary (1-carbon-14) linoleic acid in lactating cows. Journal of Dairy Science, v.61, n.4, p.561-565, 1978.
PANTOJA, J.; FIRKINS, J.L.; EASTRIDGE, M.L. Site of digestion and milk production by cows fed fats differing in saturation, esterefication, and chain length. Journal of Dairy Science, v.77, n.8, p.2341-2356, 1994.

RABELLO, T.G.; VALADARES FILHO, S.C.; SILVA, J.F.C. et al. Grão de soja moído na alimentação de vacas em lactação I. Consumos, produção e composição do leite. Revista da Sociedade Brasileira de Zootecnia, v.25, n.2, p.345-356, 1996.

SAS/STAT User's Guide. Release 6.03 Edition. Cary: [s.n.], 1989. $1500 \mathrm{p}$.

SCHAUFF, D.J.; ELLIOTT, J.P.; CLARK, J.H. et al. Effects of feeding lactating dairy cows diets containing whole soybeans and tallow. Journal of Dairy Science, v.75, n.7, p.1923$1935,1992$.

SCHINGOETHE, D.J.; CASPER, D.P. Total lactational response to added fat during early lactation. Journal of Dairy Science, v.74, n.8, p.2617-2622, 1991.

SMITH, N.E.; COLLAR, L.S.; DUNKLEY, W.L. et al. Digestibility and effects of whole cottonseed fed to lactating cows. Journal of Dairy Science, v.64, n.11, p.2209-2215, 1981.

STERN, M.D.; SANTOS, K.A.; SATTER, L.D. Protein degradation in rumen and amino acid absorption in small intestine of lactating dairy cattle fed heat-treated whole soybeans. Journal of Dairy Science, v.68, n.1, p.45-56, 1985.

TEDESCO, M.J.; VOLKWEISS, S.J.; BOHNEN, H. Análises do solo, plantas e outros materiais. Porto Alegre: Universidade Federal do Rio Grande do Sul, 1985. 118p. (Boletim Técnico de Solos, 5)

UMPHREY, J.E.; MOSS, B.R.; CUMMINGS, K.A. et al. Effects of whole cottonseed, megalac or the combination on lactational performance of dairy cows during summer months. Journal of Dairy Science, v.72, n.8, p.2205, 1989.

Van SOEST, P.J. Nutritional ecology of the ruminant. 2.ed Cornell: Materials, 1994. 476p.

WU, Z.; HUBER, J.T. Relationship between dietary fat supplementation and milk protein concentration in lactating cows: a review. Livestock Production Science, v.39, p.141-155, 1994.

WU, Z.; HUBER, J.T.; SLEIMAN, F.T. et al. Effect of three supplemental fat sources on lactation and digestion in dairy cows. Journal of Dairy Science, v.76, n.11, p.35623570,1993

Recebido em: 30/10/04

Aceito em: 17/06/05 